\title{
Alcohol consumption, tobacco smoking, betel quid chewing and oral health associations with hypopharyngeal cancer among men in Central South China: a case-control study
}

This article was published in the following Dove Press journal:

Cancer Management and Research

Junfeng Zeng

Yaoyun Tang

Ping Wu

Xing Fang

Wei Wang

Yuhua Fan

Xin Li

Suping Zhao

Department of Otorhinolaryngology Head and Neck Surgery, Province Key Laboratory of Otolaryngology Critical Diseases, Xiangya Hospital of Central South University, Changsha, People's Republic of China
Correspondence: Ping Wu

Department of Otorhinolaryngology Head and Neck Surgery, Province Key Laboratory of Otolaryngology Critical Diseases, Xiangya Hospital of Central South University, No. 87 Xiangya Road, Kaifu District, Changsha, People's

Republic of China

Email wupingcsu@hotmail.com
Background: Hypopharyngeal cancer has relatively high incidence rates in China, especially in high-risk areas. However, data on the role of major risk factors in these areas of China are still limited.

Methods: We have evaluated the roles of alcohol, tobacco and betel quid consumption, and oral health, based on 278 hypopharyngeal cancer cases and 693 controls from two centers in Central South China. The odds ratio (OR) and 95\% confidence interval (CI) values were estimated using logistic regression.

Results: We found that alcohol drinkers had a risk of hypopharyngeal cancer that was up to seven times higher than that for those who had never drunk. A very strong effect of traditional liquor as compared to other alcohol types was observed, with the OR reaching 11.26 (CI 6.53-19.41) for this cancer. Tobacco smokers were up to four times more likely to develop hypopharyngeal cancer than never smokers. The OR for betel quid chewing was 1.86 (CI 1.26-2.75) as compared to never users. Poor oral hygiene had a risk of hypopharyngeal cancer that was two times higher than that for normal oral hygiene.

Conclusion: In this study, we have shown for what is believed to be the first time the association of increased hypopharyngeal cancer incidence with alcohol, tobacco, betel quid and oral hygiene in China. Alcohol may play a larger role for hypopharyngeal cancer in this population than in populations in other areas.

Keywords: alcohol, tobacco, betel quid, oral hygiene, hypopharyngeal cancer

\section{Introduction}

Hypopharyngeal cancer is ararecancer, accounting for approximately $3-5 \%$ of all head and neck cancers (HNCs); ${ }^{1,2}$ approximately 2,500 new cases are diagnosed in the United States each year. ${ }^{2}$ The peak incidence of hypopharyngeal cancer is at age 50-60 years; this cancer is more common in men, but is rarely found in women. ${ }^{3}$

Numerous epidemiological studies have consistently demonstrated overall alcohol consumption and tobacco use are the main risk factors associated with this cancer, and clear dose-response relationships and interaction between alcohol and tobacco consumption contribute to increase the risk for this cancer. ${ }^{4,5}$ In addition, recent studies found that betel quid chewing is another lifestyle risk for hypopharyngeal cancer. ${ }^{6,7}$ However, the relative contribution of these risk factors varies with different countries and geographical areas. In Europe, alcohol and tobacco are 
estimated to be responsible for $84 \%$ of all $\mathrm{HNC}$, and for $83 \%$ of the disease in Latin America, whereas they are responsible for $51 \%$ of $\mathrm{HNC}$ in the United States. ${ }^{8}$ Although previous research has identified alcohol and tobacco as being associated with an increase in hypopharyngeal cancer, other factors, such as type of alcohol, betel quid chewing and oral hygiene, have not been fully considered for this cancer. In addition, only one study reported an increased cancer risk and tobacco smoking, alcohol drinking and betel quid chewing in head and neck cancers (including 81 cases of hypopharyngeal cancer) in an East China population. ${ }^{7}$ Few studies of population attributable risk estimates are available for Chinese people at present. In this work, we conducted apopulation-based case-control study to specifically assess the role of alcohol consumption, tobacco smoking, betel quid chewing and oral hygiene in the development of hypopharyngeal cancer in two institution centers in Central South China.

\section{Materials and methods}

\section{Study population}

A population-based case-control study was conducted in Central South China from 2011 to 2018 to investigate the effects of lifestyle and habit on hypopharyngeal carcinomain males. In the case group, the individuals were all males aged between 30 and 85 years at the time of diagnosis, with hypopharyngeal carcinoma histologically confirmed by pathologists between June 2011 and June 2018. All eligible cases' date was obtained from medical record system. To avoid missing data due to incomplete medical records, telephone interviews performed within 6 months of cancer diagnosis. Controls, who were matched to the cases by age ( \pm 3 years) and gender, were selected from diseases unrelated to alcohol, tobacco, or dietary practices in two hospital centers. For the case group, a total of 339 patients (261 from the Xiangya Hospital and 78 from the Second Xiangya Hospital) were eligible; among them, 278 patients' complete date was collected. For the controls, a total of 767 male individuals participated in the questionnaire survey; among them, 693 individuals were eligible. A total of 278 eligible cases and 693 controls were recruited in this study, and the proportion for patients/controls was $1 / 2.5$. All patients and controls had written informed consent to participate in this study, and that it was conducted in accordance with the Declaration of Helsinki. Ethics approval for the study was obtained from the ethics committees at Xiangya Hospital.

\section{Data collection}

Data regarding the general characteristics (degree of education, height and weight, residence, income level and oral hygiene) and habits (alcohol consumption, tobacco smoking and betel quid chewing) of the patients were recorded in the questionnaire. Data on alcohol consumption included the individuals' ages at having their first drink, type of alcoholic beverage, frequency of drinking, volume per drink, duration and year of quitting alcohol consumption. Alcohol consumption was defined as drinking an alcoholic beverage one or more times per month for more than 1 year in a lifetime. Questions regarding the type of alcoholic beverage included whether the following were consumed: traditional liquor (made in small workshops with crude manufacturing process), commercial liquor (made in distilleries with standard manufacturing process), beer, wine, and both traditional liquor and commercial liquor. The type of alcohol was determined as drinking a particular alcohol for more than 6 months. To standardize cumulative alcohol consumption for each beverage type, the amount of alcohol consumed was converted into ethanol grams as follows: commercial liquor contains $52 \%$ alcohol by volume (ABV), with $25 \% \mathrm{ABV}$ for traditional liquor, $12 \% \mathrm{ABV}$ for wine and $5 \% \mathrm{ABV}$ for beer (we merged the two latter varieties because the sample size of wine was small). The ABV values of traditional liquor and commercial liquor were the mean of 71 samples that were measured by alcohol meter, which were provided by the patients and local liquor producers. The ABV values of beer and wine have been referenced in other papers. ${ }^{9,10}$ One standard glass of liquor is equivalent to $15.6 \mathrm{~mL}$ pure ethanol according to a large study. ${ }^{10}$ Accumulation of alcohol was calculated by the average number of glasses of liquor per day and the duration of alcohol consumption. Quitting drinking more than a year before the interview (for the controls) or the diagnosis date (for the cases) was considered as cessation. The number of years of quitting was the total number of years of cessation in the time period.

Data on tobacco and betel quid consumption included age at first exposure, number of packets (20 cigarettes per packet for tobacco and approximately $30 \mathrm{~g}$ per packet for betel) consumed daily, duration of exposure and year of quitting. Smoking was defined as having smoked more than 100 cigarettes in a lifetime. Cumulative smoking was denoted by pack-years of tobacco smoking. Betel quid chewing was defined as chewing at least once a day 
for more than 1 year. Cumulative chewing was denoted by pack-years of betel quid consumption. Quitting smoking or chewing more than a year before the interview (for the controls) or the diagnosis date (for the cases) was considered to be cessation of smoking or chewing. The number of years of quitting was the total number of years of cessation in the time period.

Due to the lack of availability of a previously validated scoring system, we used a self-reported composite oral-score by reference to another study to evaluate oral hygiene. ${ }^{11}$ This oral-score ranged from 0 to 3 (with a score of 2 or 3 indicating poor oral hygiene). Oral-scoring criteria included: the selfreported number of teeth missing due to periodontal disease $(0-5=0,>5=1)$; regular daily brushing (yes $\left.=0, n_{0}=1\right)$; regular visits to the dentist during the decade before diagnosis or interview (once or more $=0$, none $=1$ ).

\section{Formaldehyde measurement}

3, 5-Diacetyl-1, 4-dihydropyridine compoundsare produced by the reaction of acetylacetone and formaldehyde in excess ammonium acetate solution, which is a stable substance with a maximum absorption wavelength at $415 \mathrm{~nm}$. Thus, we assessed the formaldehyde concentration in alcoholic beverages by spectrophotometer. Formaldehyde standard solutions with a gradient of different concentrations $(0.0 \mathrm{mg} / \mathrm{L}, \quad 0.12 \mathrm{mg} / \mathrm{L}, \quad 0.4 \mathrm{mg} / \mathrm{L}$, $1.2 \mathrm{mg} / \mathrm{L}, 2.6 \mathrm{mg} / \mathrm{L}, 5.2 \mathrm{mg} / \mathrm{L}$ in $10 \%, 25 \%$ and $40 \%$ vol ethanol) were prepared from a $37 \%$ formaldehyde stock solution and 95\% ethyl alcohol. Standard acetylacetonesolution was prepared by dissolving $50 \mathrm{~g}$ ammonium acetate, $6 \mathrm{~mL}$ acetic acid and $0.5 \mathrm{~mL}$ acetylacetone in $600 \mathrm{~mL}$ distilled water. All reagents were purchased from Macklin (Shanghai, China). Standard acetylacetone solution $(6 \mathrm{~mL})$ was added to test tubes to prepare standard reaction tubes. Formaldehyde standard solution $(5 \mathrm{~mL})$ of different concentrations was added into six separate standard reaction tubes. The mixed solutions were heated to $100{ }^{\circ} \mathrm{C}$ for 10 mins. A spectrophotometer (BioTek Instruments, USA) was used to measure the absorbance of the different mixed solutions at $415 \mathrm{~nm}$ after cooling. The same method was used to obtain the absorbance of 71 traditional and commercial liquor samples. A standard curve was drawn and the formaldehyde concentrations of the samples determined. To avoid the influence of impurities in the alcohol, $6 \mathrm{~mL}$ buffer solution was added into each sample without acetylacetone for measurement of the baseline absorbance. Formaldehyde accumulation (g) for the individuals was estimated from the formaldehyde concentration of the liquor that the person had drunk, the volume consumed per day and the duration of drinking.

\section{Statistical analysis}

The relationship between the risk of hypopharyngeal carcinoma and drinking, smoking, betel quid chewing and other characteristics (degree of education, body mass index (BMI), residence, income level and oral hygiene) was assessed. Unconditional logistic regression analysis was used to estimate odds ratios (ORs) and 95\% confidence intervals (CI) for the risk of hypopharyngeal carcinoma being associated with drinking alcohol, smoking status, betel quid chewing and oral hygiene. For all models, age groups were adjusted because of frequency matching. Tobacco smoking, alcohol consumption, betel quid chewing and oral hygiene, which were deemed of special interest (based on clinical experience), were all mutually adjusted for each other. Then, all covariates that proved statistically significant by Pearson $\chi^{2}$ test were added in the final multivariable model. Covariates were identified as follows: degree of education (less than primary school, junior and senior high school, more than junior college), BMI ( $\mathrm{kg} / \mathrm{m} 2)$, residence (rural vs urban), income level (RMB, the currency of China) and oral hygiene (normal oral hygiene vs poor oral hygiene), alcohol consumption (current, ex-drinker vs nondrinker), tobacco smoking (current, ex-smoker vs nonsmoker) and betel quid chewing (current, ex-chewer vs never chewed).

The population attributable risks (PAR) were calculated by formula 1. The PAR of smoking and drinking combined was calculated by formula $2 .^{8}$ The PAR for tobacco or alcohol exposures (PAR total) was estimated with the equation below.

$$
\mathrm{PAR}=\mathrm{p}(\mathrm{ec}) \times \frac{O R-1}{O R}
$$

Formula1, $\mathrm{p}(\mathrm{ec})$ is the proportion exposed among the cases, OR adjusted for potential confounding factors were used in the equations.

$$
\begin{aligned}
P A R_{\text {total }}=1 & \\
-\left(\frac{a_{11}}{m \times O R_{11}}+\frac{a_{10}}{m \times O R_{10}}+\frac{a_{01}}{m \times O R_{01}}+\frac{a_{00}}{m \times O R_{00}}\right) & \\
P A R_{\text {tobacco and alcohol combined }}= & P A R_{\text {tobacco }}+P A R_{\text {alcohol }} \\
& -P A R_{\text {total }} \\
P A R_{\text {alcohol alone }}=P A R_{\text {alcohol }}- & P A R_{\text {tobacco and alcohol combined }} \\
P A R_{\text {tobacco alone }}= & P A R_{\text {tobacco }}-
\end{aligned}
$$


Formula 2, $\mathrm{a}_{00}=$ never tobacco/never alcohol users, $\mathrm{a}_{01}=$ never tobacco/ever alcohol users, $\mathrm{a}_{10}=$ ever tobacco/never alcohol users, and $\mathrm{a}_{11}=$ ever tobacco/ever alcohol users, $\mathrm{m}$ $=$ total number of cases.

The Wilcoxon rank sum test was used to compare the formaldehyde concentration in traditional liquor and commercial liquor, the data did not have a normal distribution when analyzed by Kolmogorov-Smirnov test. The formaldehyde accumulation of liquor was calculated by daily volume consumed, duration of drinking and the median formaldehyde concentration of the liquor. All statistical analyses were completed using SPSS version 22 software (IBM, Armonk, NY, USA).

\section{Results}

Our study population was all male. The patients in the case group had a mean age of 60.0 years, while those in the control group had a mean age of 58.5 years, cases and controls were comparable for age. For the case group, participants had lower BMIs and education levels, and were more likely to come from a rural area with worse socioeconomic status. For the controls, people had higher BMIs and education levels, and were more frequently from urban areas with better socioeconomic status (Table 1).

\section{Alcohol consumption}

Alcohol drinkers had an increased risk of developing hypopharyngeal cancer, with an adjusted OR of 7.37 (95\% CI: 4.44-12.24), while alcohol drinking in $92.8 \%$ of the cases and $54.3 \%$ of the controls. The increase in risk was larger for those who started drinking at an age of under 18 years old than for over 18 years old. The duration of drinking was also associated with increased risks, more than 39 years drinking had the strongest risk. Dose-effect relationships were evident for alcohol frequency and cumulative consumption. Quitting drinking alcohol was associated with decreased risks, longer times of drinking cessation had stronger protective effects (Table 2).

We analyzed the effect among drinkers of different types of alcohol, with never drinking as a reference category. The strongest effect was observed for drinkers of traditional alcohols, and the strength of the association was not changed by adjusting for drinking quantity or total alcohol consumed. The consumption of traditional and commercial alcohol was the second strongest risk effect for drinkers. There was also an increase in risk with commercial alcohols, although the OR was a little smaller compared to traditional alcohols or traditional and
Table I Distributions of selected characteristics among cases and controls

\begin{tabular}{|c|c|c|c|}
\hline Characteristics & $\begin{array}{l}\text { Case } \\
(n=278) n \%\end{array}$ & $\begin{array}{l}\text { Control } \\
(n=693) n \%\end{array}$ & $p$-value \\
\hline $\begin{array}{l}\text { Age (year) } \\
\quad \leq 50 \\
5 \mathrm{I}-60 \\
6 \mathrm{I}-70 \\
>70\end{array}$ & $\begin{array}{l}46(16.5) \\
106(38.1) \\
103(37.1) \\
23(8.3)\end{array}$ & $\begin{array}{l}139(20.1) \\
284(41.0) \\
236(34.0) \\
34(4.9)\end{array}$ & $p=0.110^{a}$ \\
\hline $\begin{array}{l}\text { BMI }(\mathrm{kg} / \mathrm{m} 2) \\
\quad<18.5 \\
\quad 18.5-24.0 \\
>24.0\end{array}$ & $\begin{array}{l}45(16.2) \\
164(59.0) \\
69(24.8)\end{array}$ & $\begin{array}{l}29(4.2) \\
409(59.0) \\
255(36.8)\end{array}$ & $p<0.000 I^{a}$ \\
\hline $\begin{array}{l}\text { Income } \\
\qquad 2000 \\
2000-4000 \\
>4000\end{array}$ & $\begin{array}{l}130(46.8) \\
106(38.1) \\
42(15.1)\end{array}$ & $\begin{array}{l}\text { I98 (28.6) } \\
\text { I. }(46.6) \\
\text { I72 (24.8) }\end{array}$ & $p<0.000 I^{a}$ \\
\hline $\begin{array}{l}\text { Education level } \\
\text { Less and primary } \\
\text { school } \\
\text { Junior and senior } \\
\text { high school } \\
\text { More and junior } \\
\text { college }\end{array}$ & $\begin{array}{l}89(32.0) \\
150(54.0) \\
39(14.0)\end{array}$ & $\begin{array}{l}137(19.8) \\
459(66.2) \\
97(14.0)\end{array}$ & $p<0.000 I^{a}$ \\
\hline $\begin{array}{l}\text { Residence } \\
\text { Rural area } \\
\text { Urban area }\end{array}$ & $\begin{array}{l}\text { I } 48(53.2) \\
\text { I } 30(46.8)\end{array}$ & $\begin{array}{l}309(44.6) \\
384(55.4)\end{array}$ & $p=0.015^{\mathrm{a}}$ \\
\hline $\begin{array}{l}\text { Alcohol drinking } \\
\text { Never } \\
\text { Ever }\end{array}$ & $\begin{array}{l}20(7.2) \\
258(92.8)\end{array}$ & $\begin{array}{l}317(45.7) \\
376(54.3)\end{array}$ & $p<0.000 I^{a}$ \\
\hline $\begin{array}{l}\text { Tobacco smoking } \\
\text { Never } \\
\text { Ever }\end{array}$ & $\begin{array}{l}18(6.5) \\
260(93.5)\end{array}$ & $\begin{array}{l}239(34.5) \\
454(65.5)\end{array}$ & $p<0.000 I^{a}$ \\
\hline $\begin{array}{l}\text { Areca chewing } \\
\text { Never } \\
\text { Ever }\end{array}$ & $\begin{array}{l}197(70.9) \\
81(29.1)\end{array}$ & $\begin{array}{l}577(83.3) \\
116(16.7)\end{array}$ & $p<0.000 I^{a}$ \\
\hline $\begin{array}{l}\text { Oral hygiene } \\
\text { Normal oral hygiene } \\
\text { Poor oral hygiene }\end{array}$ & $\begin{array}{l}200(71.9) \\
78(28.1)\end{array}$ & $\begin{array}{l}472(68.1) \\
84(12.1)\end{array}$ & $p<0.000 I^{a}$ \\
\hline
\end{tabular}

Note: ${ }^{\text {a }}$ earson $\chi^{2}$ test was used to compare the differences between the case and control.

commercial alcohols. Beer and wine conferred least risk effect for drinkers (Table 2).

It was interesting that traditional liquor drinking had a much higher risk for hypopharyngeal cancer than commercial liquor $(\mathrm{OR}=11.26,95 \% \mathrm{CI} 6.53-19.41$ and $\mathrm{OR}=6.63$, 95\% CI3.76-11.69, respectively, Table 2). Formaldehyde has been classified as carcinogenic to humans (World 
Table 2 The risk of alcohol consumption in hypopharyngeal cancer

\begin{tabular}{|c|c|c|c|c|}
\hline Variable & Case(n) & Control (n) & Adjust $\mathrm{OR}^{\mathrm{a}}(\mathbf{9 5 \% \mathrm { Cl } )}$ & $p$-value \\
\hline Alcohol drinking & & & & $p<0.000 I^{b}$ \\
\hline Never & 20 & 317 & I (reference) & \\
\hline Ever & 258 & 376 & $7.37(4.44-12.24)$ & \\
\hline Age at starting drinking & & & & $P_{\text {trend }}<0.000 I^{c}$ \\
\hline Never drinking & 20 & 317 & I (reference) & \\
\hline$\leq 18$ & 58 & 80 & $9.20(5.01-16.91)$ & \\
\hline$>18$ & 200 & 296 & $6.89(4.10-11.56)$ & \\
\hline Duration, year & & & & $p_{\text {trend }}<0.000 I^{c}$ \\
\hline Never drinking & 20 & 317 & I (reference) & \\
\hline$\leq 20$ & 58 & 104 & 6.62 (3.66-II.99) & \\
\hline $21 \sim 39$ & 127 & 211 & 6.71 (3.92-11.47) & \\
\hline$>39$ & 73 & 61 & $10.44(5.64-19.32)$ & \\
\hline Ethanol-grams, daily & & & & $P_{\text {trend }}<0.0001^{c}$ \\
\hline Never drinking & 20 & 317 & I (reference) & \\
\hline$\leq 20$ & 46 & 195 & $2.71(1.50-4.89)$ & \\
\hline $21-80$ & 110 & 138 & $8.67(5.00-15.04)$ & \\
\hline$>80$ & 102 & 43 & $27.31(14.62-51.02)$ & \\
\hline Cumulative, glass-year & & & & $p_{\text {trend }}<0.0001^{c}$ \\
\hline Never drinking & 20 & 317 & I (reference) & \\
\hline$<25$ & 19 & 169 & $1.37(0.69-2.72)$ & \\
\hline $25-124$ & 110 & 133 & $9.34(5.39-16.19)$ & \\
\hline$>124$ & 129 & 74 & $18.16(10.25-32.15)$ & \\
\hline Quitting years & & & & $p_{\text {trend }}=0.0056^{c}$ \\
\hline Continue drinking & 207 & 273 & I (reference) & \\
\hline $1-4$ & 29 & 51 & $0.60(0.35-1.02)$ & \\
\hline $5-9$ & 16 & 30 & $0.70(0.36-1.36)$ & \\
\hline$>9$ & 6 & 22 & $0.30(0.12-0.80)$ & \\
\hline Drinking cessation & 51 & 103 & $0.72(0.58-0.90)$ & \\
\hline \multicolumn{5}{|l|}{ Alcohol type } \\
\hline Never drinking & 20 & 317 & I (reference) & \\
\hline Traditional liquor(TL) ${ }^{d}$ & 134 & 134 & $11.26(6.53-|9.4|)$ & $p<0.000 I^{b}$ \\
\hline Commercial liquor(CL) & 77 & 126 & $6.63(3.76-11.69)$ & $p<0.000 \mathrm{I}^{\mathrm{b}}$ \\
\hline $\mathrm{TL} \& \mathrm{CL}$ & 36 & 60 & $7.53(3.84-14.79)$ & $p<0.000 I^{b}$ \\
\hline Beer and wine & 11 & 56 & $2.42(1.06-5.56)$ & $p=0.0368^{b}$ \\
\hline
\end{tabular}

Notes: ${ }^{a}$ Adjusted for BMI, income, chewing andsmoking habits, and oral hygiene. ${ }^{b}$ Estimates from multivariate unconditional logistic regression equations. ${ }^{c} p_{\text {trend }}$ was calculated by unconditioned logistic regression after converting the variable into ranked data. ${ }^{\mathrm{d}}$ Traditional Liquoris defined as made in small workshops with crude manufacturing process, commercial Liquor is defined as made in distilleries with standard manufacturing process.

Abbreviations: TL, traditional liquor; $\mathrm{CL}$, commercial liquor.

Health Organization-International Agency for Research on Cancer (IARC) group 1), and relatively high concentrations of formaldehyde are found in alcoholic beverages. To investigate whether the difference in risk might be due to differences in formaldehyde consumption between drinkers of different alcohol types, an analysis of the concentration of formaldehyde in two types of alcoholic samples was conducted. There was a difference in the formaldehyde concentration level between traditional liquor and commercial liquor $(0.63 \mathrm{mg} / 1$ vs. $0.44 \mathrm{mg} / \mathrm{l}$, respectively, $p=0.045$, Figure 1). Moreover, both the frequency of alcohol consumption and the weekly volume of alcohol drunk were larger for traditional liquor than for commercial liquor in cases and controls (Table S1).

\section{Tobacco smoking}

A history of tobacco smoking was associated with an increased hypopharyngeal cancer risk with OR 4.35 (95\% CI: 2.51-7.53, Table 3). Those who started smoking at an age under 18 years old had higher risks than those 


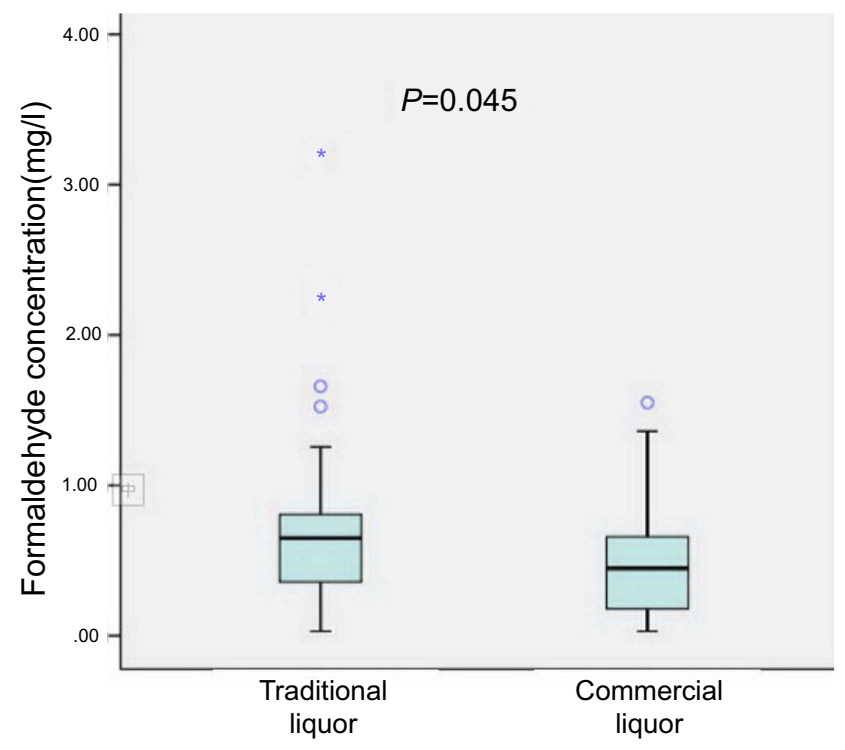

Figure I Comparison of formaldehyde concentration in traditional liquor and commercial liquor samples. Formaldehyde concentration in traditional liquor samples $(n=38)$ was higher than that in commercial liquor samples $(n=33, p=0.045)$. $p$ value was tested by Wilcoxon rank sum test. Circles represent outlier value, asterisks represent extreme value.

whose starting age was over 18 years old. A significant dose-response relationship was found between smoking duration and hypopharyngeal cancer risk. The frequency and cumulative consumptionfor smoking cigarettes both presented a clear dose-effect relationship for increasing the risk. A significant protective effect of quitting smoking was observed for hypopharyngeal cancer (Table 3).

\section{Alcohol-tobacco interaction}

$25.5 \%$ of the cases in our study were attributable to the use of alcohol alone and $17.5 \%$ to the use of tobacco alone, whereas $54.5 \%$ of cases were attributable to the combined use of alcohol and tobacco. The combined use of alcohol and tobacco had a strong increased association with hypopharyngeal cancer risk $(\mathrm{OR}=9.84,95 \%$ CI 6.49-14.92), and alcohol alone also had a positive association with risk $(\mathrm{OR}=3.41,95 \% \mathrm{CI} 1.13-10.27)$, whereas there was a non-significant association between tobacco use alone and hypopharyngeal cancer (Table 4A). In an interaction analysis using age term, the risk increased with older age ( $\geq 60$ ) exposing to both alcohol and tobacco (PAR 62.1\% vs $51.4 \%$, Table $4 \mathrm{~B}$ ).

\section{Betel quid chewing}

Betel quid chewing was associated with an increased risk of hypopharyngeal cancer $(\mathrm{OR}=1.86,95 \%$ CI1.26-2.75), accounting for $29.1 \%$ of cases compared to $16.7 \%$ of controls. A dose-response relationship was also detected for betel quid chewing duration, frequency and cumulative consumption, which all increased the risk of hypopharyngeal cancer. Quitting betel quid chewing for more than 5 years had a protective effect; however, there was no significant association between quitting for less than 5 years and the cancer risk (Table 5A).

\section{Oral hygiene}

Poor oral hygiene had an increased risk of hypopharyngeal cancer $(\mathrm{OR}=2.07,95 \%$ CI 1.37-3.14), with poor oral hygiene in $28.1 \%$ of the cases and $15.2 \%$ of the controls. Tooth loss of more than five teeth had an increased risk for this cancer. However, neither the frequency of dental visits nor tooth brushing had a significantly reduced risk association with hypopharyngeal cancer (Table 5B).

\section{Discussion}

There is an independent and dose-responsive association of alcohol consumption and cigarette smoking with cancer of the hypopharynx in American and European populations. ${ }^{8}$ However, the data on the role of these two carcinogens in China are still quite limited. To date, the most extensive epidemiologic studies of HNC in China have frequently investigated the oral cavity and oropharynx sites, with only a small number of cases of hypopharyngeal cancer. Only a few studies have specifically addressed the situation in the hypopharynx. To the best of our knowledge, this work is the most comprehensive study ever conducted investigating the role of alcohol, tobacco, betel quid chewing and oral hygiene in the development of hypopharyngeal cancer in high-risk areas in China.

An association between socioeconomic status, including income, education level and residence, and hypopharyngeal cancer risk was found in this study, as well as in age- and BMI-adjusted analyses including all the cases and controls. Our findings demonstrated a higher risk of hypopharyngeal cancer among lower socioeconomic groups, which was similar with colorectal cancer studies. ${ }^{12}$

Our risk estimates for alcohol consumption were relatively high in this study, the rate of which was at the extreme as high as $92.8 \%$ in the cases. Alcohol alone had a strong effect, with an adjusted OR of 11.26 for the highest alcohol consumption category. This is higher than that reported in European, American, Indian and East Asian studies, ${ }^{7,10,13}$ and this is probably due to the differences in dietary habits in different areas. However, a strong alcohol effect in heavy drinkers was observed in 
Table 3 The risk of tobacco consumption in hypopharyngeal cancer

\begin{tabular}{|c|c|c|c|c|}
\hline Variable & Case (n) & Control (n) & Adjust OR(95\% Cl) & $p$-value \\
\hline Tobacco smoking & & & & $p<0.000 I^{b}$ \\
\hline Never & 18 & 239 & I (reference) & \\
\hline Ever & 260 & 454 & $4.35(2.5 \mathrm{I}-7.53)$ & \\
\hline Age at starting smoking & & & & $P_{\text {trend }}=0.0004^{c}$ \\
\hline Never smoking & 18 & 239 & I (reference) & \\
\hline$\leq 18$ & 87 & 114 & $5.67(3.07-10.46)$ & \\
\hline$>18$ & 173 & 340 & $3.89(2.22-6.82)$ & \\
\hline Duration, year & & & & $p_{\text {trend }}<0.0001^{c}$ \\
\hline Never smoking & 18 & 239 & I (reference) & \\
\hline$\leq 20$ & 36 & 104 & $3.11(1.58-6.11)$ & \\
\hline $21 \sim 39$ & 121 & 224 & $4.28(2.40-7.64)$ & \\
\hline$>39$ & 103 & 126 & $5.25(2.87-9.60)$ & \\
\hline Cigarette, daily & & & & $P_{\text {trend }}<0.0001^{c}$ \\
\hline Never smoking & 18 & 239 & I (reference) & \\
\hline$<20$ & 44 & 92 & $3.09(1.60-5.96)$ & \\
\hline $20-39$ & 150 & 286 & $4.25(2.4 I-7.50)$ & \\
\hline$>39$ & 66 & 76 & $6.40(3.35-12.21)$ & \\
\hline Cumulative, pack-year ${ }^{d}$ & & & & $P_{\text {trend }}<0.0001^{\mathrm{C}}$ \\
\hline Never smoking & 18 & 239 & I (reference) & \\
\hline$\leq 20$ & 43 & 91 & $3.56(1.83-6.93)$ & \\
\hline $20-39$ & 97 & 189 & $4.22(2.33-7.62)$ & \\
\hline$>39$ & 120 & 174 & $4.87(2.7 \mathrm{I}-8.74)$ & \\
\hline Quitting years & & & & $P_{\text {trend }}=0.0097^{c}$ \\
\hline Continue smoking & 225 & 328 & I (reference) & \\
\hline $1-4$ & 12 & 56 & $0.35(0.17-0.73)$ & \\
\hline $5-9$ & 13 & 33 & $0.60(0.28-1.26)$ & \\
\hline$>9$ & 10 & 37 & $0.5 I(0.23-1.15)$ & \\
\hline Smoking cessation & 35 & 126 & $0.74(0.59-0.93)$ & \\
\hline
\end{tabular}

Notes: ${ }^{a}$ Adjusted for BMI, income, chewing and smoking habits, and oral hygiene. ${ }^{b}$ Estimates from multivariate unconditional logistic regression equations. ${ }^{c} P_{\text {trend }}$ was calculated by unconditioned logistic regression after converting the variable into ranked data. ${ }^{\mathrm{d}} 20$ cigarettes in a pack.

previous studies from Japan. ${ }^{5}$ A clear dose-effect relationship was confirmed for alcohol quantity, drinking duration and total alcohol consumed, which were not fully investigated in any of the previous studies.

With respect to alcohol types, we observed a strong effect of traditional liquor as compared to other types of alcohol; traditional liquor is the predominant type of alcoholic beverage in rural areas in Central South China. There was little evidence of the importance of alcohol types in hypopharyngeal cancer in any of the previous studies. As the hypopharynx belongs to the upper aerodigestive tract, hypopharyngeal cancer may have similar risk factor patterns to esophageal cancers (ECs). Studies from northern Italy reported increased risks of EC for wine and grappa drinkers. ${ }^{14}$ Whereas spirits increased the risk for EC in China compared to wine and beer. ${ }^{15}$ In Latin America, aperitifs and spirits had a stronger effect than other types of alcohol in cancers of the hypopharynx and larynx, with an OR of 3.90. ${ }^{9}$ This difference may be due to different drinking patterns and/or different types of alcoholic beverage that are consumed as compared to other areas. As formaldehyde is a common impurity in alcoholic beverages and classified by the IARC as carcinogenic to humans (group 1), we might hypothesize that the stronger effect of traditional liquor found in our study could be the result of relatively high concentrations of formaldehyde, with respect to the other less strong types of alcohol consumed. In order to investigate this, we determined the concentration of formaldehyde in different traditional and commercial liquor samples. The results showed that traditional liquor contained a higher concentration of formaldehyde than commercial liquor. Moreover, traditional liquor drinkers tended to have a higher frequency and greater cumulative consumption of the alcohol. Therefore, 
Table 4 Alcohol consumption and tobacco smoking interaction parameters and attributable risks for hypopharyngeal cancer by age

\begin{tabular}{|c|c|c|c|c|c|}
\hline Variable & Case (n) & Control (n) & Adjust OR(95\%Cl) ${ }^{a}$ & $p_{\text {-value }}{ }^{b}$ & PAR $^{c}$ \\
\hline A. Never alcohol and tobacoo & 6 & 156 & I (reference) & & \\
\hline Alcohol alone & 12 & 83 & $3.41(1.13-10.27)$ & 0.0295 & $25.5 \%$ \\
\hline Tobacco alone & 14 & 161 & $2.21(0.76-6.44)$ & 0.1472 & $17.5 \%$ \\
\hline Tobacco and alcohol combined & 246 & 293 & $9.84(6.49-14.92)$ & $<0.0001$ & $54.5 \%$ \\
\hline Total & 278 & 693 & & & \\
\hline \multicolumn{6}{|l|}{ B. Less than 60} \\
\hline Never alcohol and tobacoo & 5 & 91 & I (reference) & & \\
\hline Alcohol alone & 9 & 61 & $3.56(0.91-13.89)$ & 0.0676 & $26.5 \%$ \\
\hline Tobacco alone & 10 & 100 & $2.11(0.61-7.33)$ & 0.2421 & $18.5 \%$ \\
\hline Tobacco and alcohol combined & 128 & $|7|$ & $7.51(4.56-12.36)$ & $<0.0001$ & $51.4 \%$ \\
\hline Total & 152 & 423 & & & \\
\hline \multicolumn{6}{|l|}{ Older than 60} \\
\hline Never alcohol and tobacoo & 1 & 65 & I (reference) & & \\
\hline Alcohol alone & 3 & 22 & $9.50(0.86-105.36)$ & 0.0668 & $20.9 \%$ \\
\hline Tobacco alone & 4 & 61 & $5.02(0.44-57.48)$ & 0.1945 & $12.5 \%$ \\
\hline Tobacco and alcohol combined & 118 & 122 & |7.06(7.7|-37.74) & $<0.0001$ & $62.1 \%$ \\
\hline Total & 126 & 270 & & & \\
\hline
\end{tabular}

Notes: ${ }^{a}$ Adjusted for BMI, income, chewing and smoking habits, and oral hygiene. ${ }^{b}$ Estimates from multivariate unconditional logistic regression equations. ${ }^{c}$ PAR, population attributable risk.

we speculated that the sustained and higher amount of formaldehyde intake in traditional liquor drinking may be the cause of the increased hypopharyngeal cancer risk.

With regard to smoking history, we found that tobacco use increased the risk more than fourfold. Our results are slightly high compared with pooled data from 15 case-control international studies, which reported the risk with an OR of 2.02 for cancers from oropharynx and hypopharynx sites, ${ }^{10}$ but less than that observed in black HNC cases in the United States. ${ }^{16}$ In addition, the association between tobacco and hypopharyngeal cancer is not as large as that observed in a Japanese study. ${ }^{5}$ A dose-effect relationship between different smoking parameters and $\mathrm{HNC}$ risk has been shown in previous studies, but the evidence from China was not very consistent. Our results demonstrate a clear dose-effect relationship between smoking duration and the risk of hypopharyngeal cancer, as well as tobacco frequency and cumulative consumption.

We have also found that quitting alcohol drinking or tobacco smoking attenuates the risk of hypopharyngeal cancer. A protective effect of smoking or alcohol drinking cessation has already been reported in HNCs in other studies, ${ }^{9,17}$ with an independent protective effect of quitting either of the two habits.

An important finding from our study was the multiplicative effect of alcohol and tobacco observed on hypopharyngeal cancer risk. Alcohol alone had an effect, but with the exclusion of tobacco smoking, the association between alcohol consumption and cancer risk was much weaker. As for tobacco smoking, there was no significant association between tobacco use alone and hypopharyngeal cancer. It is possible that this is due to the small number of cases of smoking alone in our study. Nevertheless, it is also plausible that tobacco smoking on its own is not an important risk factor for hypopharyngeal cancer. Although tobacco was considered to the primary carcinogen in HNC from previous studies, ${ }^{10,17}$ our results indicate alcohol but not tobacco is the most important risk factor for hypopharyngeal cancer. In other studies, ${ }^{10,13}$ absence of tobacco use, the association between alcohol consumption and the risk of $\mathrm{HNC}$ is apparent only at high doses and long drink-years for pharyngeal and oral cavity cancers, which suggests that they are the sites within the head and neck that are most sensitive to the carcinogenicity of alcoholic beverages.

Betel quid chewing is common in South China and South-East Asia. It contributes to a large number of HNC cases and areca nut is classified as carcinogenic to humans by the IARC (a group 1 agent). ${ }^{18,19}$ Our study showed a significant association between chewing betel quid and hypopharyngeal cancer, with an OR of 1.86 . The duration of chewing, frequency and cumulative consumption of betel quid all showed a dose-effect relationship with cancer in this study. Similar results to ours have been observed in studies from India and Taiwan, ${ }^{20,21}$ which showed a higher risk associated with betel quid for oral and hypopharyngeal 
Table 5 Betel quid consumption and oral health with the risk of hypopharyngeal cancer

\begin{tabular}{|c|c|c|c|c|}
\hline Variable & Case (n) & Control (n) & Adjust OR(95\%Cl) ${ }^{a}$ & $p$-value \\
\hline \multicolumn{5}{|l|}{ A. Betel quid chewing } \\
\hline $\begin{array}{l}\text { Areca chewing } \\
\text { Never } \\
\text { Ever }\end{array}$ & $\begin{array}{l}197 \\
81\end{array}$ & $\begin{array}{l}577 \\
116\end{array}$ & $\begin{array}{l}\text { I (reference) } \\
\text { I.86 (1.26-2.75) }\end{array}$ & $p^{b}=0.0019$ \\
\hline $\begin{array}{l}\text { Duration, year } \\
\text { Never chewing } \\
\leq 10 \\
11 \sim 20\end{array}$ & $\begin{array}{l}197 \\
8 \\
51\end{array}$ & $\begin{array}{l}577 \\
29 \\
87\end{array}$ & $\begin{array}{l}\text { I (reference) } \\
0.96(0.38-2.45) \\
2.09(1.38-3.17)\end{array}$ & $P_{\text {trend }}=0.0008^{c}$ \\
\hline $\begin{array}{l}\text { Betel-grams,frequency } \\
\text { Never chewing } \\
<20 \\
20-39\end{array}$ & $\begin{array}{l}197 \\
20 \\
43\end{array}$ & $\begin{array}{l}577 \\
36 \\
80\end{array}$ & $\begin{array}{l}\text { I (reference) } \\
\text { I.4I }(0.70-2.80) \\
2.06(1.32-3.21)\end{array}$ & $P_{\text {trend }}=0.001 \mathrm{I}^{\mathrm{c}}$ \\
\hline $\begin{array}{l}\text { Cumulative, pack-year } \\
\text { Never chewing } \\
\leq 10 \\
11-20\end{array}$ & $\begin{array}{l}197 \\
20 \\
31\end{array}$ & $\begin{array}{l}577 \\
39 \\
77\end{array}$ & $\begin{array}{l}\text { I (reference) } \\
\text { I.39 }(0.70-2.74) \\
2.08(1.33-3.24)\end{array}$ & $P_{\text {trend }}=0.0011^{c}$ \\
\hline $\begin{array}{l}\text { Quitting years } \\
\text { Continue chewing } \\
\mathrm{I}-4 \\
>5 \\
\text { Chewing cessation }\end{array}$ & $\begin{array}{l}63 \\
12 \\
3 \\
18\end{array}$ & $\begin{array}{l}73 \\
27 \\
16 \\
43\end{array}$ & $\begin{array}{l}\text { I (reference) } \\
0.43(0.18-1.08) \\
0.21(0.06-0.74) \\
0.45(0.26-0.79)\end{array}$ & $P_{\text {trend }}=0.0068^{c}$ \\
\hline \multicolumn{5}{|l|}{ B. Oral health } \\
\hline $\begin{array}{l}\text { Oral hygiene }^{c} \\
\text { Normal oral hygiene } \\
\text { Poor oral hygiene }\end{array}$ & $\begin{array}{l}200 \\
78\end{array}$ & $\begin{array}{l}472 \\
84\end{array}$ & $\begin{array}{l}\text { I (reference) } \\
2.07(1.37-3.14)\end{array}$ & $p^{b}=0.0006$ \\
\hline $\begin{array}{l}\text { Tooth loss } \\
\text { No } \\
\text { I-5 } \\
>5\end{array}$ & $\begin{array}{l}94 \\
121 \\
63\end{array}$ & $\begin{array}{l}265 \\
220 \\
71\end{array}$ & $\begin{array}{l}\text { I (reference) } \\
\text { I.04 }(0.72-1.5 \mathrm{I}) \\
\mathrm{I} .75(\mathrm{I} .08-2.83)\end{array}$ & $P_{\text {trend }}=0.0453^{c}$ \\
\hline $\begin{array}{l}\text { Dental visits } \\
\text { No } \\
\text { Yes }\end{array}$ & $\begin{array}{l}216 \\
62\end{array}$ & $\begin{array}{l}374 \\
182\end{array}$ & $\begin{array}{l}\text { I (reference) } \\
0.79(0.54-|.| 5)\end{array}$ & $p=0.1634^{d}$ \\
\hline $\begin{array}{l}\text { Tooth Brushing } \\
\text { No } \\
\text { Yes }\end{array}$ & $\begin{array}{l}38 \\
240\end{array}$ & $\begin{array}{l}70 \\
486\end{array}$ & $\begin{array}{l}\text { I (reference) } \\
\text { I.I5 (0.72-I.85) }\end{array}$ & $p=0.8612^{d}$ \\
\hline
\end{tabular}

Notes: ${ }^{a}$ Adjusted for BMI, income, chewing and smoking habits, and oral hygiene. ${ }^{b}$ Estimates from multivariate unconditional logistic regression equations. ${ }^{c} p_{\text {trend }}$ was calculated by unconditioned logistic regression after converting the variable into ranked data. ${ }^{d} p$-values were estimated by Pearson $\chi^{2}$ test.

cancers. Our results suggest that betel quid cessation more than 5 years exerted a protective effect. However, in other studies, protective effect of betel quid cessation and a reduced HNC risk is weak and is only for those who chewed a lower amount and for a shorter duration. ${ }^{21-23}$

Associations between poor oral health and $\mathrm{HNC}$ risk have been reported in studies from several areas, including the
United States, Central Europe, Latin America, Japan and India. ${ }^{24,25}$ Oral hygiene indicators usually include missing teeth, infrequent dental visits and tooth brushing infrequency. Poor oral hygiene was more common in cases than in controls, with a more than two times increased risk association for hypopharyngeal cancer. Tooth loss ( $>5$ teeth) had a positive association with cancer risk in this study, and is 
supported by the magnitude of the increase in association when adjusted for all other oral hygiene indicators. Although dentist visits and daily tooth brushing had a reduced risk association with HNC in previous studies, ${ }^{24,25}$ there was no significant result in this study.

Overall, our results confirmed that alcohol consumption was a strong risk factor in the etiology of hypopharyngeal cancer in high-risk areas in Central South China, while tobacco smoking in combination with alcohol may also confer an important role. Other risk factors, like betel quid chewing or oral hygiene, have been proposed as important determinants of the hypopharyngeal cancer incidence. Preventive efforts to encourage current drinkers to quit alcohol consumption are likely to be the most effective way to reduce the incidence of hypopharyngeal cancer in this region.

\section{Abbreviation list}

$\mathrm{ABV}$, alcohol by volume; BMI, body mass index; $\mathrm{CI}$, confidence interval; EC, esophageal cancer; HNC, head and neck cancer; IARC, International Agency for Research on Cancer; OR, odds ratio; PAR, population attributable risk.

\section{Acknowledgments}

This research was supported by The National Natural Science Foundation of China (81302355), The Natural Science Foundation of Hunan province (12JJ5049) and the Xiangya Famous Doctors Foundation.

\section{Disclosure}

The authors report no conflicts of interests in this work.

\section{References}

1. Hall SF, Groome PA, Irish J, et al. The natural history of patients with squamous cell carcinoma of the hypopharynx. Laryngoscope. 2008;118:1362-1371. doi:10.1097/MLG.0b013e31818208e7

2. Cooper JS, Porter K, Mallin K, et al. National Cancer Database report on cancer of the head and neck: 10-year update. Head Neck. 2009;31:748-758. doi:10.1002/hed.20929

3. Uzcudun AE, Bravo Fernández P, Sánchez JJ, et al. Clinical features of pharyngeal cancer: a retrospective study of 258 consecutive patients. $J$ Laryngol Otol. 2001;115(2):112-118. doi:10.1258/0022215011907703

4. Blot WJ, McLaughlin JK, Winn DM, et al. Smoking and drinking in relation to oral and pharyngeal cancer. Cancer Res. 1988;48(11):32823287.

5. Lu Y, Sobue T, Kitamura T, et al. Cigarette smoking, alcohol drinking, and oral cavity and pharyngeal cancer in the Japanese: a populationbased cohort study in Japan. Eur J Cancer Prev. 2018;27(2):171-179. doi:10.1097/CEJ.0000000000000283
6. Chang CC, Lee WT, Lee YC, et al. Investigating the association between diet and risk of head and neck cancer in Taiwan. Oncotarget. 2017;8 (58):98865-98875. doi:10.18632/oncotarget.22010

7. Lee YA, Li S, Chen Y, et al. Tobacco smoking, alcohol drinking, betel quid chewing, and the risk of head and neck cancer in an East Asian population. Head Neck. 2019;41(1):92-102.

8. Hashibe M, Brennan P, Chuang SC, et al. Interaction between tobacco and alcohol use and the risk of head and neck cancer: pooled analysis in the International Head and Neck Cancer Epidemiology Consortium. Cancer Epidemiol Biomarkers Prev. 2009;18(2):541550. doi:10.1158/1055-9965.EPI-08-0347

9. Szymańska K, Hung RJ, Wünsch-Filho V, et al. Alcohol and tobacco, and the risk of cancers of the upper aerodigestive tract in Latin America: a case-control study. Cancer Causes Control. 2011;22 (7):1037-1046. doi:10.1007/s10552-011-9779-7

10. Hashibe M, Brennan P, Benhamou S, et al. Alcohol drinking in never users of tobacco, cigarette smoking in never drinkers, and the risk of head and neck cancer pooled analysis in the International Head and Neck Cancer Epidemiology Consortium. J Natl Cancer Inst. 2007;99 (10):777-789. doi:10.1093/jnci/djk179

11. Divaris K, Olshan AF, Smith J, et al. Oral health and risk for head and neck squamous cell carcinoma: the Carolina Head and Neck Cancer Study. Cancer Causes Control. 2010;21(4):567-575. doi:10.1007/s10552-009-9486-9

12. Huxley RR, Ansary-Moghaddam A, Clifton P, et al. The impact of dietary and lifestyle risk factors on risk of colorectal cancer: a quantitative overview of the epidemiological evidence. Int $J$ Cancer. 2009;125:171-180. doi:10.1002/ijc.24343

13. Jayalekshmi PA, Nandakumar A, Akiba S, et al. Associations of tobacco use and alcohol drinking with laryngeal and hypopharyngeal cancer risks among men in Karunagappally, Kerala, India -Karunagappally cohort study. PLoS One. 2013;8(8):e73716. doi:10.1371/journal.pone.0073716

14. Zambon P, Talamini R, La Vecchia C, et al. Smoking, type of alcoholic beverage and squamous-cell oesophageal cancer in northern Italy. Int J Cancer. 2000;86(1):144-149. doi:10.1002/(SICI)10970215(20000401)86:1<144::AID-IJC23>3.0.CO;2-B

15. Gao YT, McLaughlin JK, Blot WJ, et al. Risk factors for esophageal cancer in Shanghai, China. I. Role of cigarette smoking and alcohol drinking. Int J Cancer. 1994;58:192-196.

16. Voltzke KJ, Lee YA, Zhang ZF, et al. Racial differences in the relationship between tobacco, alcohol, and the risk of head and neck cancer: pooled analysis of US studies in the INHANCE Consortium. Cancer Causes Control. 2018;29(7):619-630. doi:10.1007/s10552-018-1026-z

17. Hashibe M, Boffetta P, Zaridze D, et al. Contribution of tobacco and alcohol to the high rates of squamous cell carcinoma of the supraglottis and glottis in Central Europe. Am J Epidemiol. 2007;165 (7):814-820. doi:10.1093/aje/kwk066

18. IARC. Betel-quid and areca-nut chewing and some areca-nut derived nitrosamines. IARC Monogr Eval Carcinog Risks Hum. 2014;85:1334.

19. IARC. Personal habits and indoor combustions. Volume 100 E. A review of human carcinogens. IARC Monogr Eval Carcinog Risks Hum. 2012;100(Pt E):1-538.

20. Guha N, Warnakulasuriya S, Vlaanderen J, et al. Betel quid chewing and the risk of oral and oropharyngeal cancers: a meta-analysis with implications for cancer control. Int J Cancer. 2014;135(6):14331443. doi: $10.1002 /$ ijc. 28643

21. Wu YH, Yen CJ, Hsiao JR, et al. A comprehensive analysis on the association between tobacco-free betel quid and risk of head and neck cancer in Taiwanese men. PLoS One. 2016;11(10):e0164937. doi:10.1371/journal.pone. 0164937

22. Balaram P, Sridhar H, Rajkumar T, et al. Oral cancer in southern India: the influence of smoking, drinking, paan-chewing and oral hygiene. Int J Cancer. 2002;98(3):440-445. doi:10.1002/ijc.10200 
23. Znaor A, Brennan P, Gajalakshmi V, et al. Independent and combined effects of tobacco smoking, chewing and alcohol drinking on the risk of oral, pharyngeal and esophageal cancers in Indian men. Int $J$ Cancer. 2003;105(5):681-686. doi:10.1002/ijc.11061

24. Hashim D, Sartori S, Brennan P, et al. The role of oral hygiene in head and neck cancer: results from International Head and Neck Cancer Epidemiology (INHANCE) consortium. Ann Oncol. 2016;27 (8):1619-1625. doi:10.1093/annonc/mdw141
25. Gupta B, Bray F, Kumar N, Johnson NW. Associations between oral hygiene habits, diet, tobacco and alcohol and risk of oral cancer: a case-control study from India. Cancer Epidemiol. 2017;51:7-14. doi:10.1016/j.canep.2017.09.003 


\section{Supplementary material}

Table SI Comparison of traditional and commercial liquor consumptive volume

\begin{tabular}{|l|l|l|l|}
\hline Variable & $\begin{array}{l}\text { Case } \\
(\mathbf{n})\end{array}$ & $\begin{array}{l}\text { Control } \\
(\mathbf{n})\end{array}$ & $\begin{array}{l}\mathbf{p}^{\mathbf{a}} \\
\text { value }\end{array}$ \\
\hline $\begin{array}{l}\text { Alcohol volume (TL, L/week) } \\
<0.1\end{array}$ & 0 & 23 & \\
$0.1-$ I & 23 & 35 & $<0.000$ I \\
I-2 & 56 & 33 & \\
$>2$ & 55 & 13 & \\
\hline Alcohol volume (CL, L/week) & & & \\
$<0.1$ & 1 & 30 & \\
$0.1-$ I & 34 & 47 & $<0.000$ I \\
I-2 & 27 & 21 & \\
$>2$ & 15 & 2 & \\
\hline
\end{tabular}

Note: ${ }^{a} \mathrm{P}$-values were estimated by Pearson $\chi^{2}$ test to compare the difference between case and control TL, traditional liquor; CL, commercial liquor

\section{Publish your work in this journal}

Cancer Management and Research is an international, peer-reviewed open access journal focusing on cancer research and the optimal use of preventative and integrated treatment interventions to achieve improved outcomes, enhanced survival and quality of life for the cancer patient.

The manuscript management system is completely online and includes a very quick and fair peer-review system, which is all easy to use. Visit http://www.dovepress.com/testimonials.php to read real quotes from published authors. 